Federal Reserve Bank of Minneapolis

Research Department Staff Report 257

January 1999

\title{
Malthus to Solow
}

\author{
Gary D. Hansen*
}

UCLA

\author{
Edward C. Prescott* \\ Federal Reserve Bank of Minneapolis \\ and University of Chicago
}

\begin{abstract}
A unified growth theory is developed that accounts for the roughly constant living standards di splayed by world economies prior to 1800 as well as the growing living standards exhibited by modern industrial economies. Our theory also explains the industrial revolution, which is the transition from an era when per capita incomes are stagnant to one with sustained growth. We use a standard growth model with one good and two available technologies. The first, denoted the Malthus technology, requires land, labor, and reproducible capital as inputs. The second, denoted the Solow technology, does not require land. We show that in the early stages of development, only the Malthus technology is used, and, due to population growth, living standards are stagnant despite technological progress. Eventually, technological progress causes the Solow technology to become profitable, and both technologies are employed. In the limit, the economy behaves like a standard Solow growth model.

*We acknowledge the excellent research assistance provided by Antoine Martin and Daria Zakharova. We are also grateful to Gregory Clark for useful comments and for providing us with some of the data used in Section 2, and to Tim Kehoe for helpful discussion. The views expressed herein are those of the authors and not necessarily those of the Federal Reserve Bank of Minneapolis or the Federal Reserve System.
\end{abstract}




\section{Introduction}

This paper provides a unified theory that can account for the secular properties, or growth facts, of economic time series as observed in most, if not all, world economies prior to 1800, as well as the properties of time series observed in modern industrialized economies. Prior to 1800, living standards were roughly constant: per capita wage income, output, and consumption did not grow. Modern industrial economies, on the other hand, enjoy seemingly endless growth in living standards. In addition, the theory provided in this paper explains the industrial revolution, which is the transition from an era when per capita incomes are stagnant to one with sustained growth. In our model, given that we have abstracted from institutions that may inhibit technology adoption, this transition is inevitable, given positive rates of total factor productivity growth. In particular, at the time of the transition, there is no change in the structure of the economy (parameters describing preferences, technology, and policy), and the equilibrium implied by our theory is unique.

The model we construct combines features of a modern Solow growth model with features of one that is Malthusian in spirit. The latter model can account for the growth facts of a pre-1800 economy, while the former describes properties of modern industrial economies. This is done by introducing two technologies into a standard general equilibrium growth model [the model of Diamond (1965)]. The same good is produced by both technologies and total factor productivity grows exogenously in both sectors. One of these, denoted the Malthus technology, is a constant returns to scale production process with land, labor, and reproducible capital as inputs. Here, we are effectively modeling production as taking place on family farms and in workshops. An important feature is that land, unlike capital, is a fixed factor that cannot be produced and does not depreciate. The other, denoted the Solow technology, is similar to the first, except that only labor and capital are used. Production in this sector can be interpreted as being carried out in factories, where entry or exit occurs depending on the profitability of operating an additional factory. 
We show that along the equilibrium growth path, only the Malthus technology is used in the early stages of development when the stock of useable knowledge is small. During these stages, if we assume that population grows at the same rate as output, the living standard is constant. Eventually, as useable knowledge grows, the Solow technology begins to be used. That is, portions of the available labor and capital are employed in this sector. At this point, living standards begin to improve, and population growth has less influence on the growth rate of per capita income. In the limit, the economy behaves like a standard Solow growth model, which displays many of the same secular properties as modern industrial economies.

The inevitable transition from a land-based agrarian economy to a modern industrial economy requires, in our model, that the rate of total factor productivity growth in the Solow sector be positive in periods prior to the adoption of the Solow technology. That is, the Solow technology must improve sufficiently over time so that it ultimately becomes profitable to shift resources into this previously unused sector. Consistent with this idea, Mokyr (1990, p. 6), who documents technological progress over the past 25 centuries, notes that "much growth...is derived from the deployment of previously available information rather than the generation of altogether new knowledge." The fact that living standards began to grow following the adoption of the Solow technology has nothing to do, however, with the rate of technological progress in the Solow sector relative to that in the Malthus sector. The existence of growing living standards depends only on shifting away from the land-intensive Malthus technology to one that is capital-intensive. The rate of increase in living standards does depend on the rate of technological progress in the Solow sector.

\footnotetext{
${ }^{1}$ Of course, some technological advancements, the wheelbarrow, for example, increased total factor productivity in both sectors. The invention was employed in the agrarian sector long before the industrial revolution. This invention did, however, improve the nascent (but as yet unemployed) industrial sector as well. As Mokyr (1990) and others have clearly documented, technological advancement did not begin with the industrial revolution. Of course, once the Solow technology began to be used, the advantages of "learning by doing" and more immediate economic payoff almost certainly increased the rate of technological growth in this sector.
} 
The issue addressed in this paper is related to the issue motivating Lucas (1998), but our approach differs sharply from his. Lucas (1998) is concerned with explaining differences in population dynamics that differentiate the preindustrial revolution era from the modern era, and as a result, endogenous fertility and human capital accumulation play central roles in his analysis. In particular, Lucas (1998) constructs a model economy that, depending on the value of a certain parameter governing the private return to human capital accumulation, can exhibit either Malthusian or modern features. The approach taken by Lucas (1998) is related to the approach of Becker, Murphy, and Tamura (1990), who also emphasize the importance of fertility and human capital investment choices. In their interpretation, the Malthusian and modern eras are different steady states of the same model. In both of these papers, the transition from an economy with stable living standards to one with growing living standards requires a change in the return to human capital accumulation. The transition from Malthus to Solow is not an equilibrium property of these models, as it is in our theory. ${ }^{2}$

Laitner (1998) employs an approach similar to ours to explain why savings rates tend to increase as an economy develops. Like us, he studies an economy that can display equilibria in which a land-intensive production process is used exclusively in the early stages of development, and as technology improves, a capital-intensive technology is eventually employed as well. However, the transition to the capital-intensive technology in Laitner's model requires that living standards grow prior to the transition. Hence, his early stage is not consistent with a Malthusian equilibrium as we define it.

The rest of this paper is organized as follows. In the next section, we discuss some empirical facts concerning preindustrial and postindustrial economies. These facts are used later to test our theory. In Section 3, the model economy is presented, and an equilibrium is defined and characterized. The methods we use to compute an equilibrium path are described in Section 4. We simulate the transition from Malthus to Solow in Section 5, and we compare our results

\footnotetext{
${ }^{2}$ Recent work by Galor and Weil (1998) and Tamura (1998) models the transition from a Malthusian to an industrial economy using a theory emphasizing human capital accumulation and endogenous fertility.
} 
with the facts discussed in Section 2. Finally, some concluding comments are provided in Section 6.

\section{The English Economy From 1250 to the Present}

\section{The Period 1265-1800}

The Malthusian model describes well the behavior of the English economy from 1250 to nearly 1800. In this period, the real wages and, more generally, the standard of living display little or no trend. Increases in the stock of useable knowledge that increased production possibilities gave rise to population growth, not to increases in living standards. During this period, there was a large exogenous shock that reduced the population significantly below trend for an extended period of time. The shock was the black death. For the extended period that population was below trend, the real wage was significantly above its normal value. This observation is just what Malthusian theory predicts. We now review evidence supporting these statements.

Figure 1 plots the real farm wage for the period $1265-1800 .^{3}$ This figure shows very little trend in the real wage over this period. The Phelps-Brown and Hopkins (1956) price index we use to deflate money wages is far from ideal. The weights used are 80 percent for food, 7.5 percent for lighting and heating, and 12.5 percent for textiles. During the period, these categories of spending constituted most expenditures of the typical craftsman or laborer. There may have been an additional modest rise in the real wage over this period due to a fall in the price of goods not in the market basket of consumables used by Phelps-Brown and Hopkins (1956) and to an increase in the quality of goods. However, a modest increase over a 535-year period is an infinitesimal growth rate.

\footnotetext{
${ }^{3}$ The English population series is from Clark (1998a) for 1265-1535 and from Wrigley et al. (1997) for 1545-1800. The nominal farm wage series is from Clark (1998b), and the price index used to construct the real wage series is from Phelps-Brown and Hopkins (1956). The data have been normalized to be 100 in 1265 and have been smoothed using the Hodrick-Prescott filter with a smoothing parameter of 100.
} 


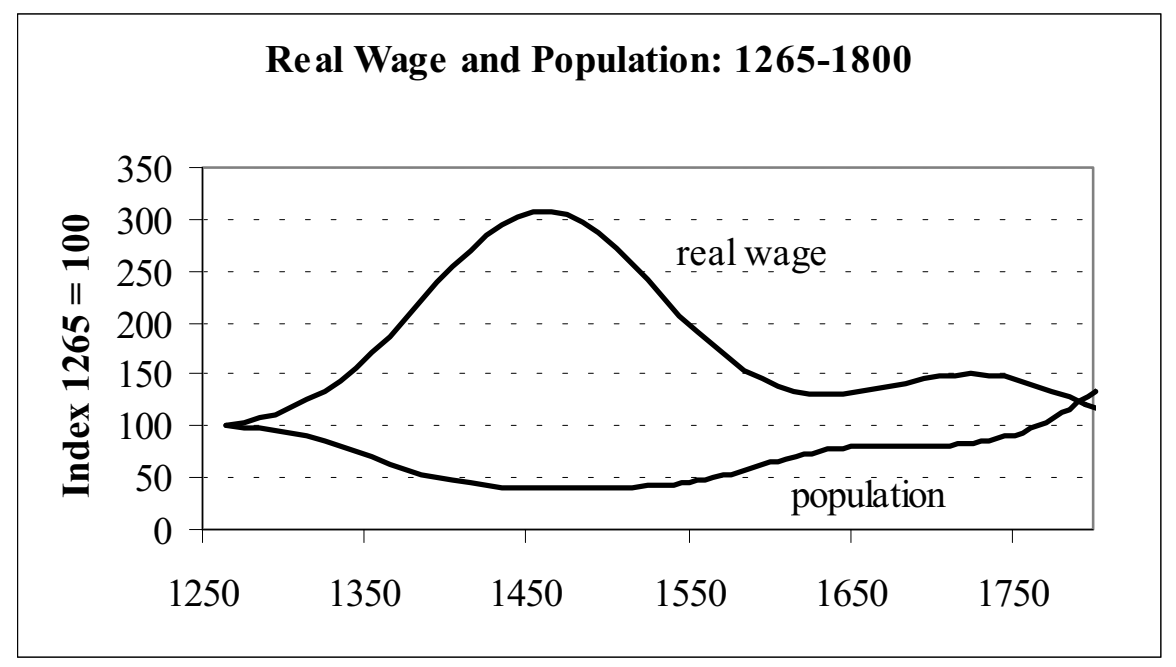

Figure 1

Figure 1 also shows dramatic opposite movements in the real farm wage and population. There is a dip in population that bottoms out around 1500 that is accompanied by an increase in the real wage. Once population begins to recover, the real wage falls. This observation is in conformity with the Malthusian theory that a drop in the population due to factors such as plague will result in a high labor marginal product, and therefore real wage, until the population recovers.

Another prediction of Malthusian theory is that land rents rise and fall with population. Figure 2 plots real land rents and population for England over the same 1265-1800 period as in Figure $1 .{ }^{4}$ The observations are in striking conformity with the theory. When population was falling in the first half of the sample, land rents fell. When population increased, land rents increased.

\footnotetext{
${ }^{4}$ The English population series and the price index used to construct the real land rent series are the same as in Figure 1. The nominal land rent series is from Clark (1998a). As in Figure 1, the data have been normalized to be 100 in 1265 and have been smoothed using the Hodrick-Prescott filter with a smoothing parameter of 100.
} 


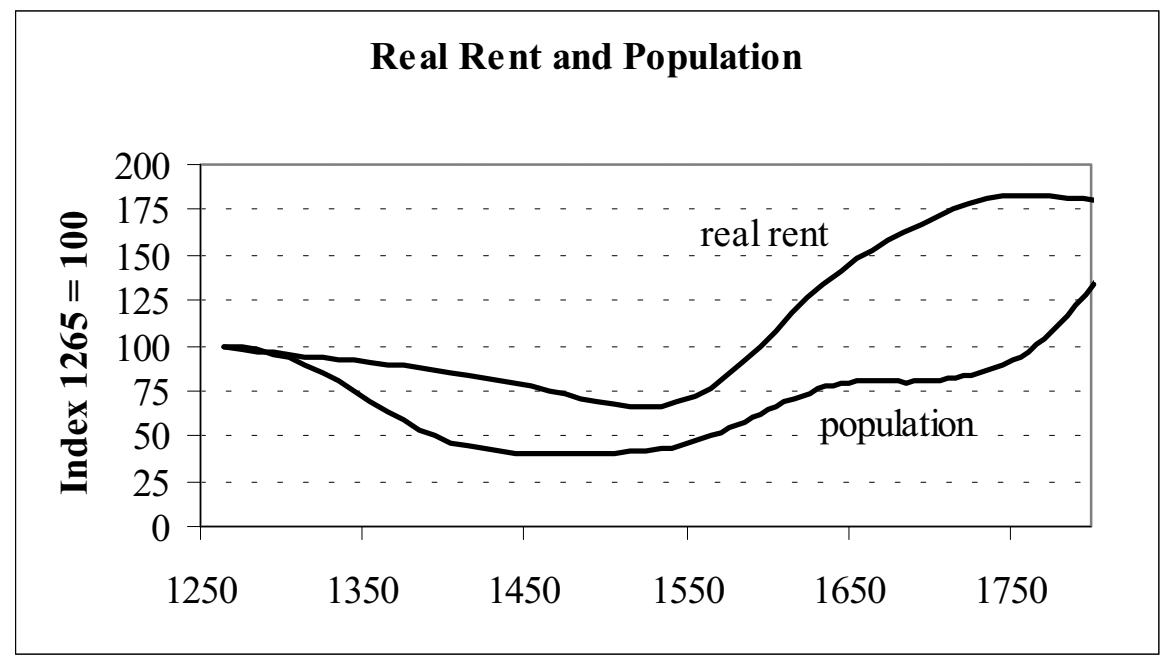

Figure 2

\section{The Period 1800-1989}

Subsequent to 1800, the Solow model describes well the behavior of the English economy. Labor productivity, which moves closely with the real wage, grew at a steady rate. Population increases did not lead to falling living standards as the Malthusian theory predicts. This is documented in Table 1, which reports English labor productivity and population for selected years. The striking observation is that labor productivity increased by a factor of 22 between 1780 and 1989. This number may underestimate the increase in the real wage because the labor share of product probably increased a little over the period. More important reasons why the increase in the real wage may be larger than this number are the difficulties of incorporating improvements in quality and the introduction of new products in any cost of living index. Nordhaus (1997) has a dramatic example of this. Using lumens as a measure of lighting, Nordhaus (1997) finds that the price of lighting fell a thousand times more than conventional lighting price indexes find. Lighting in the nineteenth century was an important component of household consumption expenditures, being almost 10 percent of total expenditures. Nordhaus (1997) also finds that the price of lighting was essentially constant between 1265 and 1800 . 


\section{Table 1}

\section{U.K. Productivity Levels}

\begin{tabular}{ccc}
\hline Year & $\begin{array}{c}\text { GDP/Hour }^{a} \\
(1985 \text { \$ U.S.) }\end{array}$ & $\begin{array}{c}\text { Population }^{b} \\
\text { (Million) }\end{array}$ \\
\hline 1700 & $0.82^{c}$ & 8.4 \\
1780 & 0.84 & 11.1 \\
1820 & 1.21 & 21.2 \\
1870 & 2.15 & 31.4 \\
1890 & 2.86 & 37.5 \\
1913 & 3.63 & 45.6 \\
1929 & 4.58 & 45.7 \\
1938 & 4.97 & 47.5 \\
1960 & 8.15 & 52.4 \\
1989 & 18.55 & 57.2 \\
\hline
\end{tabular}

${ }^{a}$ Source: Maddison (1991, pp. 274-275, 276).

${ }^{b}$ Source: Maddison (1991, pp. 227, 230-239).

${ }^{c}$ We added 5 percent to numbers for the years 1700,1780 , and 1820 to adjust for the fact that all of Ireland is included in these earlier data. The motivation for using 5 percent is that for the years 1870, 1890, and 1913, Maddison (1991) reports data with and without Southern Ireland. U.K. labor productivity without Southern Ireland was 1.05 times the U.K. labor productivity with Southern Ireland.

The U.S. Economy, 1870-1990

Another fact is that the value of farmland relative to the value of gross national product (GNP) has declined dramatically since 1870, the first year the needed census data are available, and the decline continues. Table 2 reports this ratio. 


\section{Table 2}

U.S. Farmland Value Relative to G
\begin{tabular}{cc}
\hline Year & Percentage \\
\hline 1870 & 88 \\
1900 & 78 \\
1929 & 37 \\
1950 & 20 \\
1990 & 9 \\
\hline
\end{tabular}

\footnotetext{
${ }^{a}$ Sources: U.S. Bureau of the Census (1975). Farmland values for 1990 are provided by Ken Erickson, <erickson@mailbox.econ.ag.gov>. The 1870 value of land is obtained by taking 88 percent of the value of land plus farm buildings, not including residences. In 1900 , the value of agriculture land was 88 percent of the value of farmland plus structures.
}

The decline since 1929 would have been greater if large agriculture subsidies had not been instituted. The appropriate number from the point of view of our theory, where value is the present value of marginal products, is probably less than 5 percent in 1990. The decline in farmland value relative to annual GNP from 88 percent in 1870 to less than 5 percent in 1990 is a large decline.

\section{The Model Economy}

\section{Technology}

The model economy studied is a one-good, two-sector version of Diamond's (1965) overlapping generations model. In the first production sector, which we call the Malthus sector, capital, labor, and land are combined to produce output. In the second sector, which we call the Solow sector, just capital and labor are used to produce the same good. The production functions for the two sectors are as follows: 


$$
\begin{gathered}
Y_{M t}=\gamma_{M}^{t} K_{M t}^{\phi} N_{M t}^{\mu} L_{M t}^{1-\phi-\mu} \\
Y_{S t}=\gamma_{S}^{t} K_{S t}^{\theta} N_{S t}^{1-\theta} .
\end{gathered}
$$

Here, the subscript $M$ denotes the Malthus sector and $S$ denotes the Solow sector. The variables $Y_{j}, K_{j}, N_{j}$, and $L_{j}(j=M, S)$ refer to output produced, capital, labor, and land employed in sector $j$. The parameters $\gamma_{M}$ and $\gamma_{S}$ are the total factor productivity growth factors in each sector and are each greater than one. ${ }^{5}$

Implicit behind these aggregate production functions are technologies for individual production units with the property that, given factor prices, the optimal unit size is small relative to the size of the economy and both entry and exit are permitted. The Malthus production unit can be thought of as a family farm. The Solow production unit, on the other hand, corresponds to a factory. Hence, land is an important factor of production in the Malthus production process, and reproducible capital has relatively little importance. The Solow technology is one in which the roles of these two inputs are reversed. Consistent with this interpretation, we assume that $\theta>\phi$. In fact, in our formulation of the Solow technology, land, at least when interpreted as a fixed factor, does not affect production at all.

Output from either sector can be used for consumption or investment in capital. Capital is assumed to depreciate fully at the end of each period. ${ }^{6}$ Hence, the resource constraint for the economy is given by

$$
C_{t}+K_{t+1}=Y_{M t}+Y_{S t} .
$$

\footnotetext{
${ }^{5}$ In order to keep the model simple, we have assumed a constant rate of total factor productivity growth in each sector. This assumption is not crucial to our argument. We do require a positive rate of total factor productivity growth in the Solow sector, but it need not be constant. For example, total factor productivity in this sector may grow at a relatively slow rate prior to being adopted and, due to learning by doing, may grow at a faster rate following the transition to an industrial economy.

${ }^{6}$ In the calibration exercises carried out in this paper, we interpret a period to be 35 years. Hence, the assumption of 100 percent depreciation seems empirically plausible.
} 
Land in this economy is in fixed supply: it cannot be produced and does not depreciate. We normalize the total quantity of land to be 1 . In addition, land has no alternative use aside from production in the Malthus sector.

Since the production functions exhibit constant returns to scale, we assume, for analytical convenience, that there is just one competitive firm operating in each sector. Given a wage rate $(w)$, a rental rate for capital $\left(r_{K}\right)$, and a rental rate for land $\left(r_{L}\right)$, the firm in sector $j$ solves the following problem:

$$
\max \left\{Y_{j}-w N_{j}-r_{K} K_{j}-r_{L} L_{j}\right\}, \quad j=M, S
$$

subject to the production functions (1) and (2).

\section{Preferences and Demographic Structure}

Households live for two periods and have preferences that depend on consumption in each period of life. In particular, a young household born in period $t$ has preferences summarized by the following utility function:

$$
U\left(c_{1 t}, c_{2 t+1}\right)=\log c_{1 t}+\beta \log c_{2 t+1} .
$$

Here, $c_{1 t}$ is consumption of a young household in period $t$ and $c_{2 t}$ is consumption of an old household born in period $t-1$.

The number of households born in period $t$ is denoted by $N_{t}$, where

$$
N_{t+1}=g\left(c_{1 t}\right) N_{t} .
$$

Following Malthus (1798), we assume that the population growth rate depends on the living standard, which we measure using consumption of a young household. The precise form of this functional relationship will be described in Section $5 .^{7}$

\footnotetext{
${ }^{7}$ A simple way to motivate a law of motion of this form is to allow young households to choose how many children they have. Let $n_{t+1}$ be the number of children chosen by a young household in period $t$, and suppose that the utility function of a household is given by $U\left(c_{1 t}, n_{t+1}\right)+\beta V\left(c_{2 t+1}\right)$, where $U$ is increasing and concave in both arguments. In addition, suppose that $n_{t+1}$ does not affect the budget constraint of the household. In this case, the optimality condition determining $n_{t+1}$ is $U_{2}\left(c_{1 t}, n_{t+1}\right)=0$. This equation can be solved to obtain $n_{t+1}=g\left(c_{1 t}\right)$, which implies
} 
The initial old (period $t_{0}$ ) in this economy are endowed with $K_{t_{0}} / N_{t_{0}-1}$ units of capital and $L=1 / N_{t_{0}-1}$ units of land. They rent the land and capital to firms and, at the end of the period, they sell the land to the young households. Each young household is endowed with one unit of time that can be supplied as labor to the firm. The labor income earned by the young is used to finance consumption and the purchase of capital and land, the return from which will finance consumption when old. That is, the young households maximize (5) subject to the following budget constraints:

$$
\begin{aligned}
& c_{1 t}+k_{t+1}+q_{t} l_{t+1}=w_{t} \\
& c_{2 t+1}=r_{K t+1} k_{t+1}+\left(r_{L t+1}+q_{t+1}\right) l_{t+1} .
\end{aligned}
$$

The notation employed here is to use lowercase $k$ and $l$ to denote the capital and land owned by a particular household and uppercase $K$ and $L(L=1)$ to denote the total stock of capital and land available in the economy. The letter $q$ denotes the price of land.

\section{Competitive Equilibrium}

Given $N_{t_{0}}, k_{t_{0}}$, and $l_{t_{0}}$ (where $N_{t_{0}-1} l_{t_{0}}=1$ ), a competitive equilibrium in this economy consists of sequences for $t \geq t_{0}$ of prices, $\left\{q_{t}, w_{t}, r_{K t}, r_{L t}\right\}$; firm allocations, $\left\{K_{M t}, K_{S t}, N_{M t}, N_{S t}, Y_{M t}, Y_{S t}\right\}$; and household allocations, $\left\{c_{1 t}, c_{2 t+1}, k_{t+1}, l_{t+1}\right\}$, such that the following are true:

1. Given the sequence of prices, the firm allocation solves the problems specified in equation (4).

2. Given the sequence of prices, the household allocation maximizes (5) subject to (7).

3. Markets clear: $K_{M t}+K_{S t}=N_{t-1} k_{t}$

$$
\begin{aligned}
& N_{M t}+N_{S t}=N_{t} \\
& N_{t-1} l_{t}=1 \\
& Y_{M t}+Y_{S t}=N_{t} c_{1 t}+N_{t-1} c_{2 t}+N_{t} k_{t+1} .
\end{aligned}
$$

4. $N_{t+1}=g\left(c_{1 t}\right) N_{t}$.

that $N_{t+1} \equiv N_{t} n_{t+1}=g\left(c_{1 t}\right) N_{t}$. We have found it convenient to model $g$ as an exogenous function, since we plan to calibrate the population dynamics to match historical data. 
In characterizing an equilibrium, we make use of the following results:

Proposition 1. For any wage rate $w$ and capital rental rate $r_{K}$, it is profitable to operate the Malthus sector. That is, $Y_{M t}>0$ for all $t$.

Proof: Given $w$ and $r_{K}$, when problem (4) is solved for the Malthus sector, maximum profits are equal to

$$
\Pi_{M}\left(w, r_{K}\right)=\gamma_{M}^{\frac{t}{1-\phi-\mu}}(1-\phi-\mu)\left(\frac{\phi}{r_{K}}\right)^{\frac{\phi}{1-\phi-\mu}}\left(\frac{\mu}{w}\right)^{\frac{\mu}{1-\phi-\mu}}
$$

which is clearly positive for all $t$.

A similar argument applied to the Solow sector gives the following result:

Proposition 2. Given a wage rate $w$ and capital rental rate $r_{K}$, maximized profit per unit of output in the Solow sector is positive if and only if,

$$
\gamma_{S}^{t}>\left(\frac{r_{K}}{\theta}\right)^{\theta}\left(\frac{w}{1-\theta}\right)^{1-\theta}
$$

It follows that, given $K, N$, and $t$, both sectors are operated in equilibrium ( $Y_{M}$ and $Y_{S}$ will be positive) if and only if (8) is satisfied when $w$ and $r_{K}$ are set equal to their equilibrium values in an economy with only a Malthus technology.

Given an aggregate quantity of capital and labor equal to $K$ and $N$, Proposition 2 is applied by first computing the Malthus-only wage and rental rates. These rates are

$$
\begin{aligned}
& w_{t}=\mu \gamma^{t} K_{t}^{\phi} N_{t}^{\mu-1} \\
& r_{K t}=\phi \gamma^{t} K_{t}^{\phi-1} N_{t}^{\mu} \\
& r_{L t}=(1-\phi-\mu) \gamma^{t} K_{t}^{\phi} N_{t}^{\mu} .
\end{aligned}
$$


If equation (8) is not satisfied, these rates are also the equilibrium wage and rental rates for the two-sector economy. If equation (8) is satisfied, both sectors are operated and these rates are not the equilibrium factor prices.

By the First Welfare Theorem, an equilibrium allocation has the property that resources are efficiently allocated across the two sectors. Hence, when both sectors are operated, the following problem is solved: ${ }^{8}$

$$
Y(K, N, t)=\max _{\substack{0 \leq K_{S} \leq K \\ 0 \leq N_{S} \leq N}}\left\{\gamma_{M}^{t}\left(K-K_{S}\right)^{\phi}\left(N-N_{S}\right)^{\mu}+\gamma_{S}^{t} K_{S}^{\theta} N_{S}^{1-\theta}\right\}
$$

The constraint set is compact given that the choice variables $K_{S}$ and $N_{S}$ are constrained to closed intervals. This, and the fact that the objective function is continuous, ensures the existence of an optimum. The convexity of the constraint set and strict concavity of the objective ensures uniqueness of the solution. In this case, the equilibrium wage and rental rates for the two-sector economy become

$$
\begin{aligned}
& w_{t}=\mu \gamma_{M}^{t} K_{M t}^{\phi} N_{M t}^{\mu-1}=(1-\theta) \gamma_{S}^{t} K_{S t}^{\theta} N_{S t}^{-\theta} \\
& r_{K t}=\phi \gamma_{M}^{t} K_{M t}^{\phi-1} N_{M t}^{\mu}=\theta \gamma_{S}^{t} K_{S t}^{\theta-1} N_{S t}^{1-\theta} \\
& r_{L t}=(1-\phi-\mu) \gamma_{M}^{t} K_{M t}^{\phi} N_{M t}^{\mu} .
\end{aligned}
$$

Given values for $K, N$, and $t$, the above equations determine total output, the equilibrium wage and factor rental rates, and the allocation of resources across the two sectors, $\left(K_{M}, K_{S}, N_{M}, N_{S}\right)$.

\footnotetext{
${ }^{8}$ Of course, factor allocations must solve this maximization problem whether or not both sectors are operated. However, if equation (8) is not satisfied, the optimal $K_{S}$ and $N_{S}$ are equal to 0.
} 
We now consider the household's optimization problem, which is to maximize (5) subject to (7). The first-order necessary conditions for $l_{t+1}$ and $k_{t+1}$ can be arranged to yield the following expressions:

$$
\begin{gathered}
c_{1 t}=\frac{w_{t}}{1+\beta} \\
q_{t+1}=q_{t} r_{K t+1}-r_{L t+1} .
\end{gathered}
$$

In addition, the budget constraints and market-clearing conditions imply that

$$
K_{t+1}=N_{t}\left(w_{t}-c_{1 t}\right)-q_{t}
$$

Given values for $t, K_{t}, N_{t}$, and $q_{t}$, equations (11), (12), (6), and (14) are used to obtain $w_{t}, r_{K t}, r_{L t}, c_{1 t}, N_{t+1}$, and $K_{t+1}$. Next, given these results, (11) and (13) are used to obtain $q_{t+1}$. Given values for $t_{0}, K_{t_{0}}, N_{t_{0}}$, and $q_{t_{0}}$, this procedure can, in principle, be used to obtain a sequence of endogenous variables of any length. The first three of these initial conditions can be chosen arbitrarily, although specific criteria, which we describe in the next subsection, were employed in choosing values for these initial conditions. The value of $q_{t_{0}}$ is not arbitrary, however, and must be chosen so that the resulting sequence, $\left\{q_{t}\right\}_{t=t_{0}}^{\infty}$, results in a sequence of feasible allocations. We discuss the numerical procedure employed in computing an equilibrium path in Section 4.

\section{Malthus-Only Economy}

Values for $t_{0}$ and $K_{t_{0}}\left(N_{0}\right.$ is arbitrarily set equal to 1) are chosen, following actual historical experience, so that the artificial economy is initially using only the Malthus technology. In particular, $K_{t_{0}}$ is set equal to the stock of capital in period $t_{0}$ along the asymptotic growth path of a one-sector economy with only a Malthus technology. This growth path is constructed so that household consumption $\left(c_{1 t}\right.$ and $\left.c_{2 t}\right)$ is constant in the face of productivity growth $\left(\gamma_{M}>0\right)$. This requires that the growth rate of population be equal to $\gamma_{M}^{1 /(1-\mu-\phi)}$. In addition, aggregate output, capital, consumption, the price of land, and the rental 
rate of land also grow at this rate. The wage and capital rental rates are constant. In this case, productivity increases translate directly into population increases, and there is no improvement in household living standards. This mimics the long-run growth path (abstracting from plagues and other disturbances) that actual economies experienced for centuries prior to the industrial revolution.

Let $c_{1 M}$ be the value of $c_{1 t}$ along this Malthus-only asymptotic growth path. For the twosector economy, we choose the function $g\left(c_{1 t}\right)$ in equation (6) so that $g\left(c_{1 M}\right)=\gamma_{M}^{1 /(1-\mu-\phi)}$. Since the wage and rental rates are constant along a Malthus-only balanced growth path, the Solow technology will eventually be used as long as $\gamma_{S}>1$. [See equation (8).] Once this happens, living standards will begin to improve and the population growth rate will change according to the function $g\left(c_{1}\right)$ in equation (6). Over time, as the economy develops, the fraction of labor and capital assigned to the Malthus sector, along with the price of land, will asymptotically approach zero. At this point, the economy will behave essentially like a Solow-only economy. That is, the economy will converge to a growth path along which $c_{1 t}, c_{2 t}, K_{t} / N_{t}, Y_{t} / N_{t}$, and $w_{t}$ all grow at the rate $\gamma_{S}^{1 /(1-\theta)}-1$ and $r_{K t}$ is constant. Unlike along the Malthus growth path, living standards along this asymptotic path continue to improve.

We summarize this discussion with the following proposition:

Proposition 3. Given that $g\left(c_{1 M}\right)=\gamma_{M}^{1 /(1-\mu-\phi)}$, there exists some period $t$ such that equation (8) is satisfied and the Solow technology is employed.

Hence, the transition from Malthus to Solow is inevitable.

\section{Computational Issues}

The set of equations discussed above are sufficient for determining the sequence of endogenous variables given initial values for the state variables $N$ and $K$, as well as a value for the price, $q_{t_{0}}$. In this section, we describe how we obtain $q_{t_{0}}$, as well as an entire sequence $\left\{q_{t}\right\}_{t=t_{0}}^{t_{n}}$ that satisfies the definition of an equilibrium price sequence. This requires, in particular, choosing $q_{t_{0}}$ so that $q_{t}$ is nonnegative for all $t$ and so that $K_{t+1}$, as determined by equation (14), 
does not fall below zero. The solution method that we employ is an iterative procedure designed to converge to a value of $q_{t_{0}}$ that satisfies these properties. Hence, as long as an equilibrium exists, which can be established using standard arguments, this solution procedure is able to approximate the equilibrium to the accuracy of the computer.

The solution procedure used is a shooting algorithm that is implemented as follows. Setting $K_{t_{0}}$ and $N_{t_{0}}$ as described above and letting $q_{t_{0}}=\widetilde{q}_{t_{0}}$, where $\widetilde{q}_{t_{0}}$ is the steady-state value along the Malthus-only growth path, we use equations derived in the preceding section to obtain a sequence $\left\{\widetilde{q}_{t}, \widetilde{K}_{t}, \widetilde{N}_{t}\right\}_{t=h}^{T}$. The simulation stops ( $T$ is determined) once $\widetilde{q}_{t}$ either becomes negative or becomes so large that $K_{t+1}$ is negative. If $\widetilde{q}_{t}$ becomes negative, we repeat the procedure with a larger value for $\widetilde{q}_{t_{0}}$. If $\widetilde{q}_{t}$ becomes too large, we repeat the procedure with a lower value. Through a process of iterating in this manner, we eventually bound the true value of $q_{t_{0}}$ within a very small interval. The value of $\widetilde{q}_{t_{0}}$ that is obtained once the interval is sufficiently small is stored as the first element of the sequence $\left\{q_{t}\right\}_{t=t_{0}}^{t_{n}}$; that is, we set $q_{t_{0}}=\widetilde{q}_{t_{0}}$.

Although equation (13) could, in principle, be used to obtain the subsequent elements of this sequence, this procedure would magnify the numerical errors introduced by the finite accuracy of the computer. Hence, in order to correct as much as possible for these inaccuracies, we obtain the subsequent elements of the $q$ sequence by following a procedure similar to that used to obtain the first element. In particular, we repeatedly form the sequence $\left\{\widetilde{q}_{t}, \widetilde{K}_{t}, \widetilde{N}_{t}\right\}_{t=t_{t}+1}^{T}$ in order to narrow the upper and lower bounds of $q_{t_{0}+1}$ using the shooting algorithm just described. The values for $\widetilde{K}_{t_{0}+1}$ and $\widetilde{N}_{t_{0}+1}$ in these sequences are set equal to the values of $\widetilde{K}_{t_{0}+1}$ and $\widetilde{N}_{t_{0}+1}$ found in the final iteration of the preceding step. The procedure is repeated until the entire sequence $\left\{q_{t}\right\}_{t=t_{0}}^{t_{n}}$ has been computed. Given this sequence, the remaining equilibrium prices and quantities can be computed using the equations described in the preceding section.

An advantage of our shooting algorithm is that uniqueness, or lack thereof, can be determined for the particular economy being analyzed. This is the case because the search is 
one-dimensional over possible initial prices of land. ${ }^{9}$ For the economies we studied, we found that for initial values of $q$ outside a very narrow range, the generated paths become inconsistent with equilibrium. Given existence, the equilibrium initial land price must be in this computationally determined narrow rage. Given continuity of the functions used in our shooting algorithm, equilibrium values of $K_{t+1}$ and $N_{t+1}$ have been determined to a high degree of accuracy.

\section{Quantitative Findings}

\section{Calibration}

Assuming that the economy is initially in a Malthus-only steady state, we simulate the equilibrium path for a number of periods until essentially all the available capital and labor are employed in the Solow sector. ${ }^{10}$ The model is calibrated so that (1) the Malthus-only economy is consistent with the growth facts describing the English economy prior to 1800, (2) the Solowonly economy matches the growth facts describing post-World War II industrialized economies, (3) the population growth rate reacts to changing living standards as reported in Lucas (1998), and (4) the implied annual real interest rates are reasonable given available data.

Requirement (1) is used to calibrate $\gamma_{M}, \phi$, and $\mu$, while requirement (2) is used to assign values to $\gamma_{S}$ and $\theta$. Given that we did not have good data on factor shares for the earlier period, we chose to set labor's share equal to 0.6 in both sectors, which implies values for $\mu$ and $\theta$ equal to 0.6 and 0.4 , respectively. We experimented with various low values for $\phi$, and we used a value of 0.1 in the experiment reported here. This implies that land's share in the Malthus-only economy is 0.3 .

In the pre-1800 period, we found, based on data reported in Lucas (1998), that population grew about 0.3 percent per year on average. In order that per capita income is constant in the Malthus-only economy and given that a period in our model is interpreted to be 35 years, we set

\footnotetext{
${ }^{9}$ The equilibrium conditions restrict $q_{t_{0}}$ to the closed interval $\left[0, w_{t_{0}} \beta /(1+\beta)\right]$.

${ }^{10}$ Proposition 1 implies that some fraction of total resources will always be employed in the Malthus sector, although this fraction can (and does in our simulations) converge to zero in the limit.
} 
$\gamma_{M}=1.032$. We calibrated $\gamma_{S}$ to match the growth rate of per capita GNP in the postwar period. This led us to choose $\gamma_{S}=1.518$.

We set the discount factor $\beta$ equal to 1 . This value implies annual interest rates that vary from about 2 percent in the Malthus era to between 4 and 4.5 percent in periods when the Solow technology is heavily used.

Lucas (1998) provides data on population growth rates alongside per capita GNP for various regions of the world from 1750 to the present. We use this information to calibrate the population growth function, $g\left(c_{1}\right)$. In particular, population growth rates appear to increase linearly in $c_{1}$ from the Malthus steady state to a point at which population is doubling each period (every 35 years). Over this period of rising population growth rates, living standards $\left(c_{1}\right.$ in our model) double from the Malthus steady state. After this, the population growth rate decreases linearly in $c_{1}$ until living standards are approximately 18 times what they were in the Malthus steady state. We assume that population is constant as $c_{1}$ grows beyond this point. This gives us the following form for the function $g\left(c_{1}\right)$ :

$$
g\left(c_{1}\right)= \begin{cases}\gamma_{M}^{1 /(1-\mu-\phi)}\left(2-\frac{c_{1}}{c_{1 M}}\right)+2\left(\frac{c_{1}}{c_{1 M}}-1\right) & \text { for } c_{1}<2 c_{1 M} \\ 2-\frac{c_{1}-2 c_{1 M}}{16 c_{1 M}} & \text { for } 2 c_{1 M} \leq c_{1} \leq 18 c_{1 M} . \\ 1 & \text { for } c_{1}>18 c_{1 M}\end{cases}
$$

Figure 3 graphs the function $g\left(c_{1}\right)$ against values of $c_{1} / c_{1 M}$. 


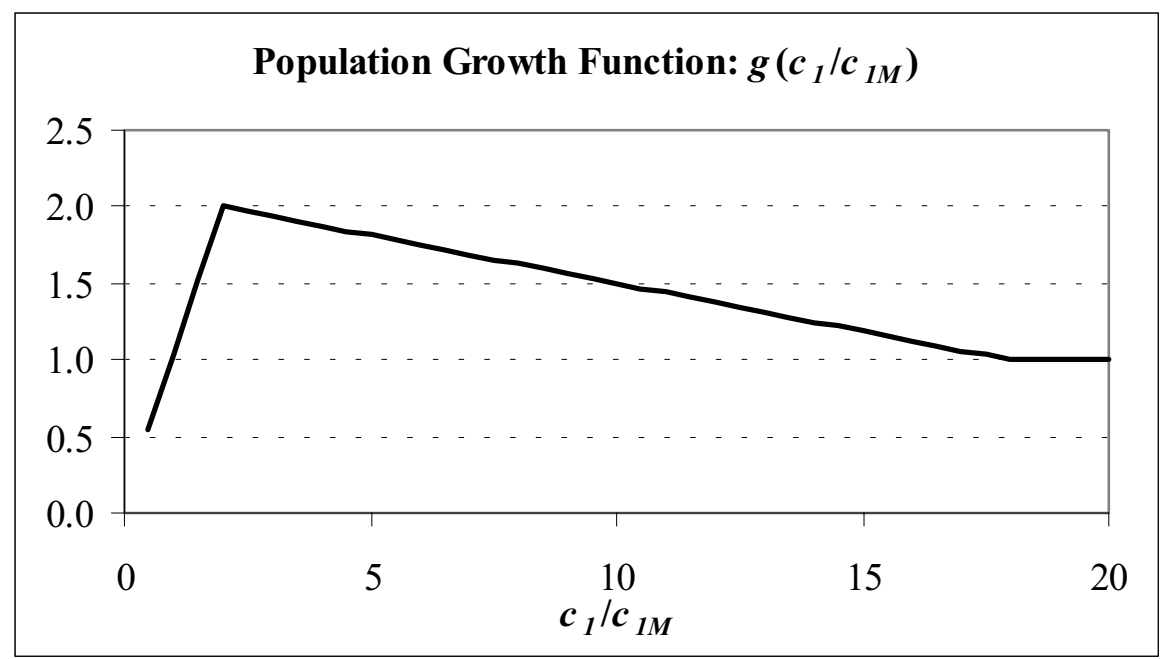

Figure 3

\section{Findings}

We simulated the economy beginning with period $t_{0}=-5$ for 11 periods, at which point the transition to the Solow technology was effectively complete. Figure 4 shows how the transition takes place by indicating the fraction of productive inputs (capital and labor) employed in the Malthus sector each period. The transition takes three generations from the point at which the Solow technology is first used until over 99 percent of the resources are allocated to the Solow sector.

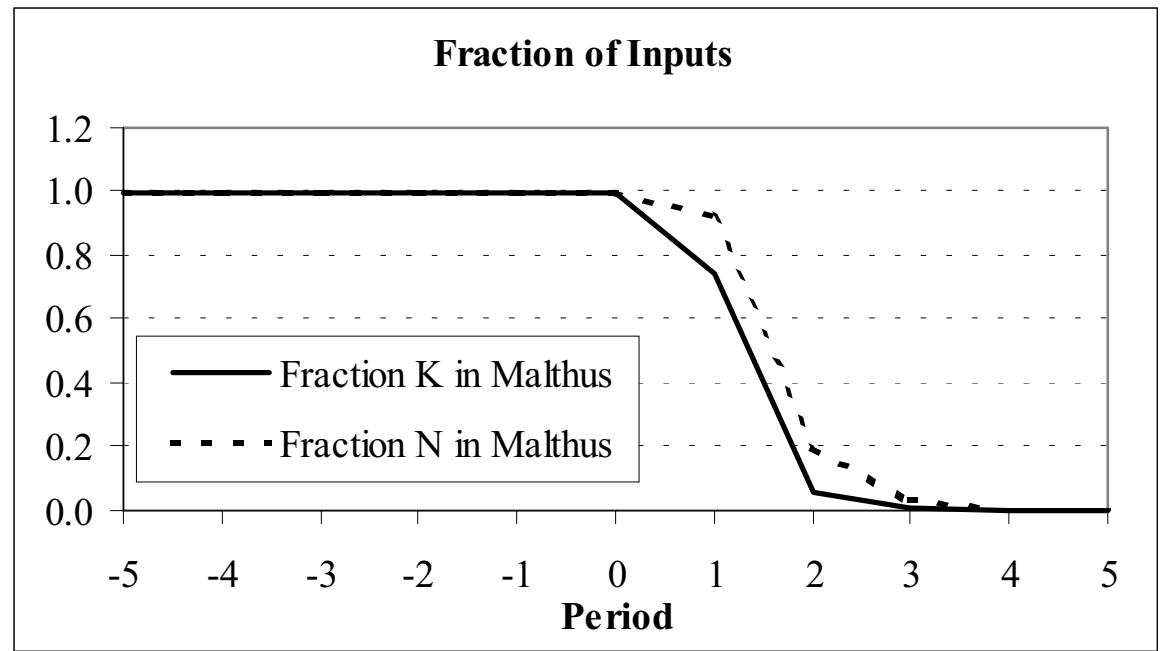

Figure 4 
Only the Malthus technology is used from period -5 to period 0 . During this time, as shown in Figure 5, output per worker remains constant. Once the industrial revolution begins in period 1, output per worker grows at increasingly higher rates. Eventually, the rate of growth will converge to the constant rate, characterizing the steady state of a Solow-only economy.

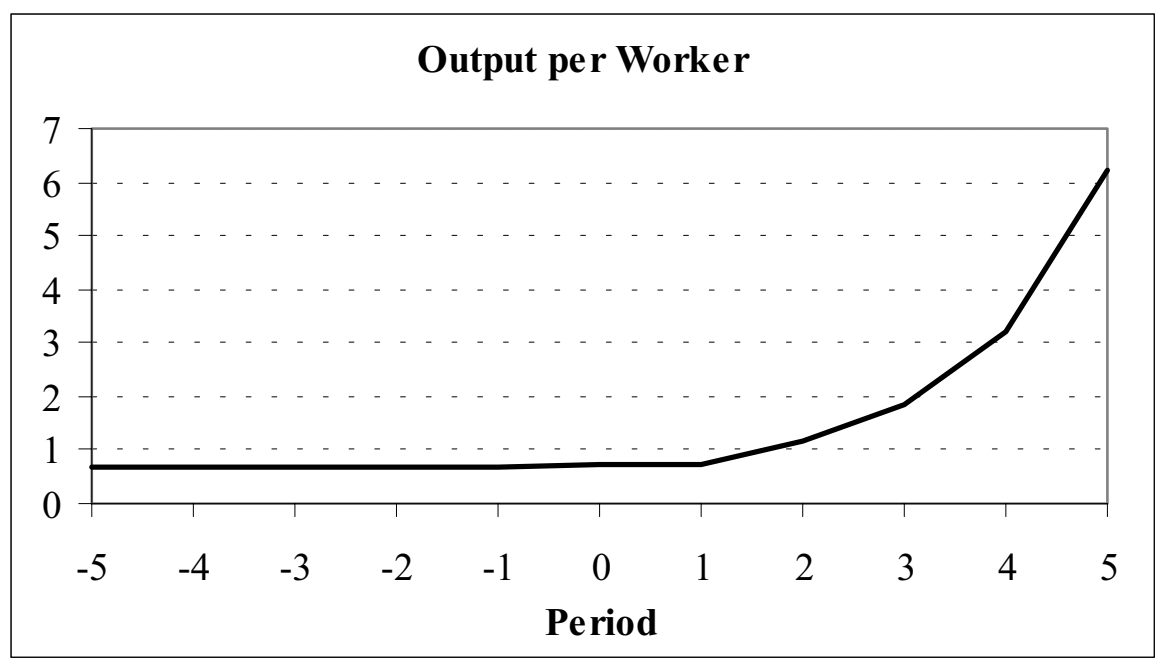

Figure 5

During the periods when only the Malthus technology is being used, population grows at the same rate as output, and the wage stays constant. After period 0, population growth increases, and the real wage increases as well. (See Figure 6, in which the wage has been normalized to one in the Malthus steady state.) This fits the pattern found in post-1800 England, as shown in Table 1. 


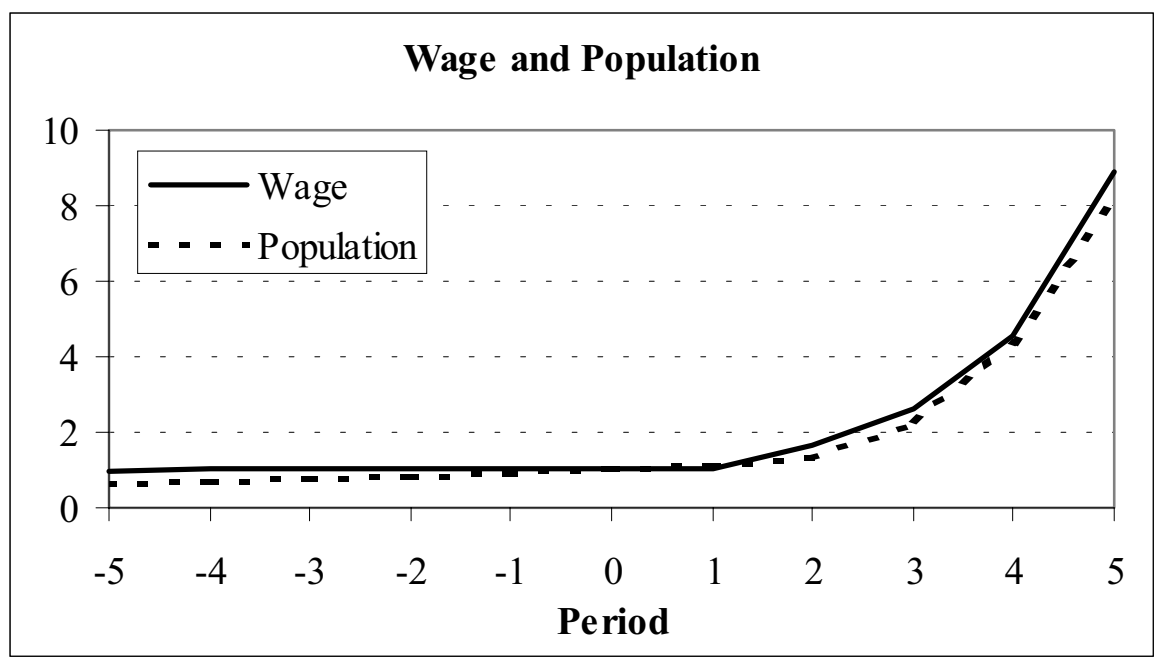

Figure 6

In addition, Figure 7 shows that the value of land relative to output decreases after the industrial revolution. Again, this is roughly consistent with the behavior of farmland values in the United States in the twentieth century. (See Table 2.)

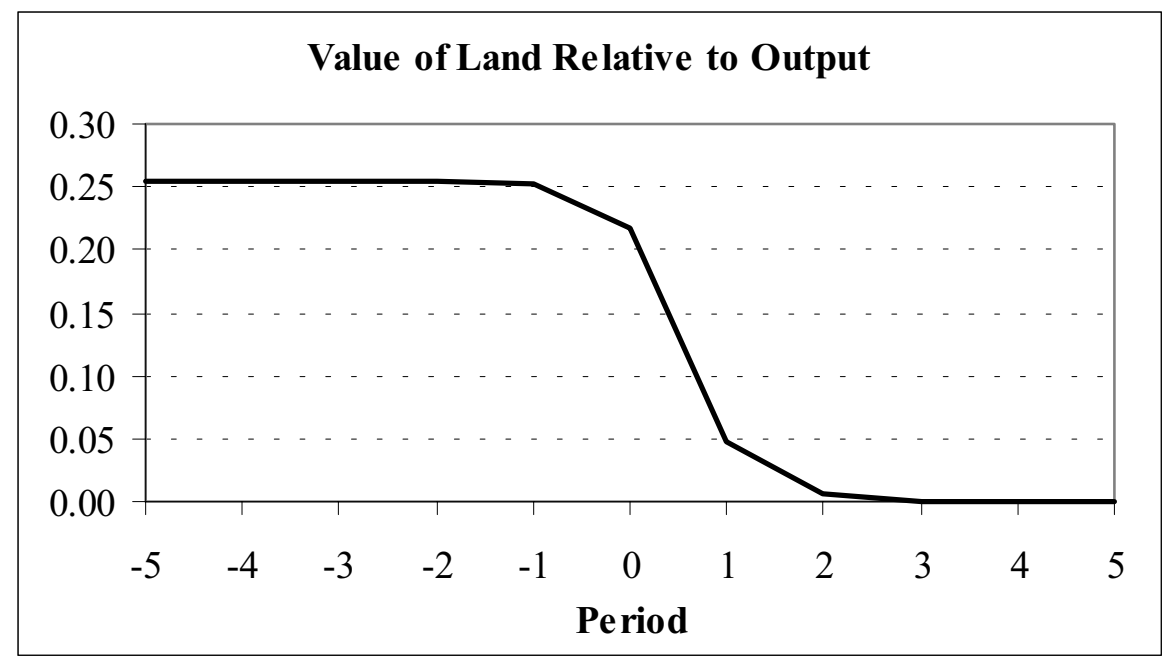

Figure 7

Finally, Figure 8 shows the population growth factor. It increases at the beginning of the industrial revolution to a maximum level, with population doubling every 35 -year period. Then the population growth rate declines as the living standard increases until five periods or 175 years after the start of the industrial revolution. 


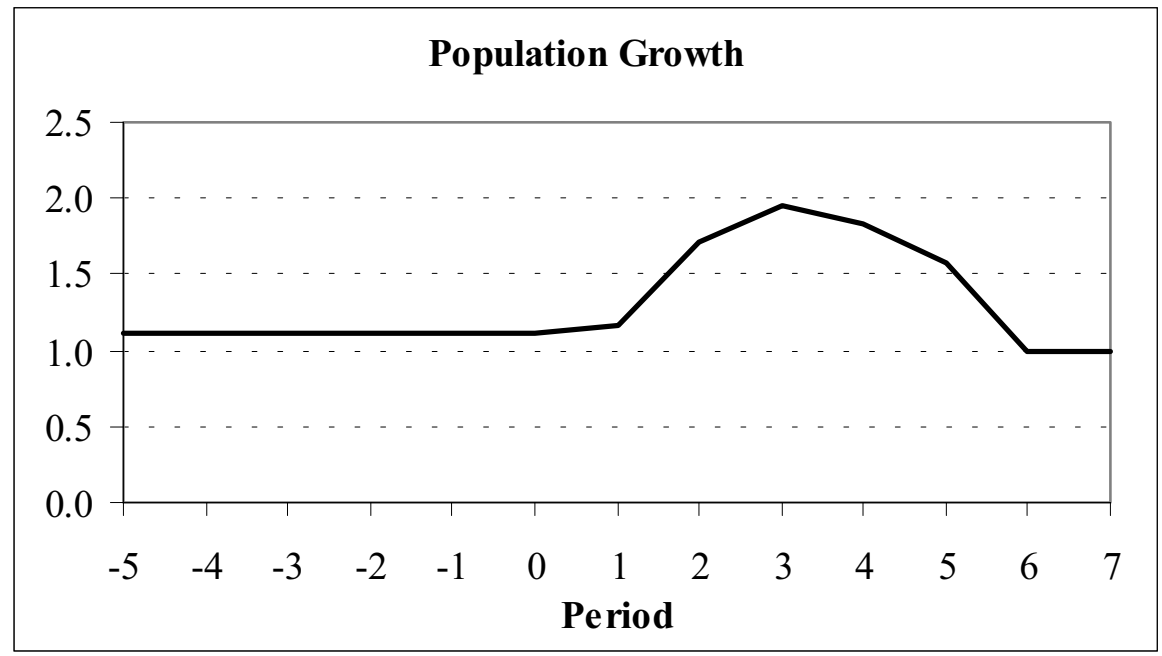

Figure 8

\section{Conclusion}

Most of the existing literature on economic growth is consistent with features of modern industrial economies, but inconsistent with the growth facts describing preindustrial economies. This includes both models based on exogenous technical progress, such as Solow (1957), and more recent models with endogenous growth, such as Romer (1986) and Lucas (1988). There also exist examples of theories consistent with facts describing the early period, yet inconsistent with features of the later period. [See Lucas (1998).] In this paper, we have presented a growth theory that is consistent with the growth facts from both periods. The transition from a preindustrial to an industrial economy, the industrial revolution, is a property of the equilibrium path associated with our theory.

We have chosen to cast our theory in the context of the overlapping generations model of Diamond (1965). We found this to be a natural way to model population growth in an equilibrium setting. We see no reason, however, why our results should not generalize to an infinite horizon context like that used in much of the growth literature - an optimal growth model with exogenous technology and population growth, for example. Our main results, as summarized in Propositions 1-3, depend primarily on properties of the technology and not at all on the length of a household's life span. 
Malthus (1798) theorized that when living standards improve, population growth rates increase. This feature is present in early stages of development as summarized in our function $g\left(c_{1}\right)$ in equation (15). However, population growth rates eventually fall and appear to level off as living standards improve after the industrial revolution. Our theory is silent as to why this occurs. Some economists, such as Becker (1960) and Lucas (1998), have argued that this may be due to a quantity-quality trade-off between the number of children a family produces versus the amount of human capital invested in each child. Other possibilities, perhaps more relevant in our context, include that the Solow technology might offer market opportunities that cause households to substitute out the home production sector into the market sector. That is, the same sorts of economic incentives that lured women into the workforce in the 1970s and 1980s may be responsible for the fall in population growth rates as living standards improve. We leave it to future work to explore these ideas.

Similarly, we have not explored the role policy might play in determining how quickly the Solow technology is adopted. For example, Parente and Prescott (1997) have studied how policy can affect the level of the total factor productivity parameter in the Solow technology. By keeping this parameter small, policy can affect when equation (8) is satisfied and, hence, when (if ever) the industrial revolutions occurs. The fact that the industrial revolution happened first in England in the early nineteenth century rather than contemporaneously or earlier in China, where the stock of useable knowledge may have actually been higher, is due perhaps to the institutions and policies in place in these two countries. 


\section{References}

Becker, Gary S. 1960. An Economic Analysis of Fertility. In Richard Easterlin, ed., Demographic and Economic Change in Developed Countries: A Conference of the Universities-National Bureau Committee for Economics. Princeton, N. J.: Princeton University Press, pp. 209-240.

Becker, Gary S., Kevin M. Murphy, and Robert Tamura. 1990. Human Capital, Fertility, and Economic Growth. Journal of Political Economy 98 (October, pt. 2): S12-S37.

Clark, Gregory. 1998a. Microbes and Markets: Was the Black Death an Economic Revolution? Unpublished manuscript (University of California, Davis).

Clark, Gregory. 1998b. Nominal and Real Male Agricultural Wages in England, 1250-1850. Unpublished manuscript (University of California, Davis).

Diamond, Peter A. 1965. National Debt in a Neoclassical Growth Model. American Economic Review 55 (December): 1126-1150.

Galor, Oded, and David N. Weil. 1998. Population, Technology, and Growth: From the Malthusian Regime to the Demographic Transition. Unpublished manuscript (Brown University).

Laitner, John. 1998. Structural Change and Economic Growth. Unpublished manuscript (University of Michigan).

Lucas, Robert E., Jr. 1988. On the Mechanics of Economic Development. Journal of Monetary Economics 22 (July): 3-42.

Lucas, Robert E., Jr. 1998. The Industrial Revolution: Past and Future. Unpublished manuscript (University of Chicago).

Maddison, Angus. 1991. Dynamic Forces in Capitalist Development: A Long Run Comparative View. Oxford and New York: Oxford University Press.

Malthus, Thomas R. 1798. An Essay on the Principle of Population. Oxford: Oxford University Press (1993 printing). 
Mokyr, Joel. 1990. The Lever of Riches: Technological Creativity and Economic Progress. Oxford and New York: Oxford University Press.

Nordhaus, William D. 1997. Do Real Output and Real Wage Measures Capture Reality? The History of Lighting Suggests Not. In Timothy F. Bresneham and Robert J. Gordon, eds., The Economics of New Goods, NBER Studies in Income and Wealth. Chicago and London: University of Chicago Press, vol. 58, pp. 29-71.

Parente, Stephen L., and Edward C. Prescott. 1997. Monopoly Rights: A Barrier to Riches. Research Department Staff Report 236, Federal Reserve Bank of Minneapolis.

Phelps-Brown, Henry, and Sheila V. Hopkins. 1956. Seven Centuries of the Prices of Consumables, Compared With Builders' Wage-Rates. Economica 23: 296-315.

Romer, Paul M. 1986. Increasing Returns and Long-Run Growth. Journal of Political Economy 94 (October): 1002-1037.

Solow, Robert M. 1957. Technical Change and the Aggregate Production Function. Review of Economics and Statistics 39 (August): 312-320.

Tamura, Robert. 1998. From Agriculture to Industry: Human Capital and Specialization. Unpublished manuscript (Clemson University).

U.S. Bureau of the Census. 1975. Historical Statistics of the United States, Colonial Times to 1970. 2 vols. Washington, D.C.: U.S. Government Printing Office.

Wrigley, E. A.; R. S. Davis; J. E. Oeppen; and R. S. Schofield, eds. 1997. English Population History From Family Reconstitution 1580-1837. New York and Cambridge: Cambridge University Press. 